\title{
A solar powered wireless computer mouse: Industrial design concepts
}

\author{
N.H. Reich ${ }^{\mathrm{a}, *}$, M. Veefkind ${ }^{\mathrm{b}}$, W.G.J.H.M. van Sark ${ }^{\mathrm{a}}$, E.A. Alsema ${ }^{\mathrm{a}}$, W.C. Turkenburg ${ }^{\mathrm{a}}$, \\ S. Silvester ${ }^{b}$ \\ a Department of Science, Technology and Society, Copernicus Institute, Utrecht University, Heidelberglaan 2, 3584 CS Utrecht, The Netherlands \\ ${ }^{\mathrm{b}}$ Industrial Design Engineering, Delft University of Technology, Landbergstraat 15, 2628 CE Delft, The Netherlands
}

Received 19 September 2007; received in revised form 2 June 2008; accepted 21 July 2008

Available online 26 September 2008

Communicated by: Associate Editor H. Gabler

\begin{abstract}
A solar powered wireless computer mouse (SPM) was chosen to serve as a case study for the evaluation and optimization of industrial design processes of photovoltaic (PV) powered consumer systems. As the design process requires expert knowledge in various technical fields, we assessed and compared the following: appropriate selection of integrated PV type, battery capacity and type, possible electronic circuitries for PV-battery coupling, and material properties concerning mechanical incorporation of PV into the encasing. Besides technical requirements, ergonomic aspects and design aesthetics with respect to good "sun-harvesting" properties influenced the design process. This is particularly important as simulations show users can positively influence energy balances by "sun-bathing" the PV mouse. A total of 15 SPM prototypes were manufactured and tested by actual users. Although user satisfaction proved the SPM concept to be feasible, future research still needs to address user acceptance related to product dimensions and user willingness to pro-actively "sun-bath" PV powered products in greater detail.
\end{abstract}

(C) 2008 Published by Elsevier Ltd.

Keywords: Device integrated PV (DIPV); PV product; PV powered; Solar powered; Green products

\section{Introduction}

The year 1957 saw the dawn of photovoltaic (PV) consumer applications through the creation of the "solar battery radio" (Acopian Inc., 2008). Just three years before, the first solar cells with reasonable efficiencies, made from crystalline silicon, were presented by the Bell laboratories (Chapin et al., 1954). Surprisingly, it took to the mid1980s for solar cells to be incorporated into consumer electronics in notable quantities. And although a seemingly endless list of PV powered consumer products is commercially available today, today's share of sold electronic consumer products that incorporate PV is very low; in fact, the

\footnotetext{
* Corresponding author. Tel.: +31 30253 7637; fax: +31 302537601 . E-mail address: N.H.Reich@uu.nl (N.H. Reich).
}

majority of sold products do not incorporate any PV. Only a single 'mainstream' $\mathrm{PV}$ powered consumer product exists: the PV calculator. This is very much in contrast to off-grid applications, where PV is almost always used, e.g., to power parking ticket vending machines or traffic sensors. Installation costs for off-grid applications powered by PV are highly competitive, as the investment for grid connections become superfluous. An overview of the many existent PV applications - for both the consumer market as well as for off-grid PV applications - was recently published (Roth, 2008).

The use of solar cells to power (small) electronic appliances can be interesting from very diverse perspectives, one being environmental concerns. Nowadays consumer products are often sold together with primary (or 'singleuse') batteries. By introducing solar cells, the need for these batteries will be reduced whilst the share of secondary 
batteries will be increased. The economic perspective is also very appealing due to the large number of potential users. In addition, consumer attitude towards photovoltaics can be positively influenced. The essential prerequisite for this is obviously that the PV powered devices must convince their users of their benefits in practical terms. Unfortunately, this is not always a given since a large proportion of the available PV rechargers and PV powered products do not function properly or have other shortcomings (Kan et al., 2004). This problem is inherent as the present knowledge-base on photovoltaics and solar powered systems is simply insufficient for optimal PV powered product design (Veefkind, 2004). This may result in poor energetic performance, which users perceive as inappropriate, especially for PV powered devices. The SYN-Energy project (Alsema et al., 2005) evolved to address these issues directly. It aims to fill the existent knowledge gaps with the development of data, tools and methods to support the developers and designer of PV powered products. Like any industrial product development project, the SYNEnergy project is of multi-disciplinary character, involving natural, technological and social scientists from three Dutch Universities (Delft University of Technology, Utrecht University and University of Twente).

To investigate industrial design processes with regards to technical engineering solutions, we selected a test product: the wireless solar powered mouse (SPM). The choice for a SPM fulfilled our aim to tackle the many problems frequently encountered by PV product designers. The key issue - to select a challenging product case - was fulfilled to such an extent, that it was initially unclear whether a SPM product is at all feasible. Variations of device use patterns and available irradiation leads to uncertain energy balances. In case of heavy device use and little irradiation it may not be possible to power a SPM on solely PV generated charge. Furthermore, the hand of the user will have to touch the SPM cover with the solar cells directly underneath, thereby reducing the amount of generated charge. Moreover, the uncertainty of the energy balance poses the question, in how far user are willing to "sun-bath" their PV powered mouse. The energy balance is thus one of the critical issues for an SPM. Integrating solar cells into a wireless computer mouse in an aesthetically pleasing and yet energetically acceptable way poses another challenge.

\section{The product design process: developing design criteria}

Exploratory studies were conducted to determine the kind of project and product the SPM idea would develop into. This so-called "quick-scan" included market research (existing products, market segmentation and corridor of price), user research (observational research, interviews and focus groups) and rough energy balance calculations (charge generation of PV indoors, device charge demands and typical use times). The "quick-scan" and the preliminary energy balance estimations (see Section 2.2) indicated the development of the "wireless pointing device" to be fea- sible. At this stage, three obvious product concepts could be distinguished:

1. An SPM that is "worry free".

2. An SPM that requires "special user-care".

3. An SPM that has a larger surface area than traditional mice.

Optimally, the SPM would be energetically self-supporting, thus not requiring any special user-care. This can only be achieved, however, if the SPM is only occasionally used (option 1). To guarantee 100\% solar operation also for medium and heavy use, the SPM requires pro-active "sun-bathing" to recharge the batteries (option 2). An alternative is to increase PV area (option 3). Inevitably, this leads to a mouse-pad-sized product, which must not require special user care due to the sheer inconvenience of "sun-bathing" a larger product. We decided to opt for option 2.

\subsection{Focus group research on SPM designs}

So-called focus group research, where several potential users are interviewed qualitatively, allows a closer interpretation of user criteria related to device designs. Previous focus group research (Elzen, 2006) highlighted that the SPM's perceived quality is greatly influenced by the integration of the PV-cell into the encasing. Fig. 1 shows three mouse designs that were assessed by potential users. According to the participants of the focus groups, the PV-cell must follow the encasing's shape. PV-cells are otherwise perceived as "vulnerable" and/or "less reliable". This is key, since the same focus group research points out that ergonomics is the user's most important criterion, with organic, rounded shapes being perceived as most attractive. It also indicates that rectangular mice, such as depicted in Fig. 1a, are not an option.

\subsection{Energy balance scenarios}

To estimate energy balances for the SPM, both the charge demand of the device and the charge generation potential of the solar cells to be incorporated had to be determined.

Market research found charge demands of commercial products to vary by a factor of 4-5. The commercially available product with the lowest power demand at the time (end of 2005), indicated in Table 1 as 'wireless optical 1', was sold by Microsoft as 'Intellimouse'. Meanwhile, energetically more economic mice operating with a laser instead of a light emitting diode (LED) have been introduced. However, the SPM product is based on 'Intellimouse' electronics and consequently LED technology. Charge demand ranges can easily be calculated based on expected device use times between 4 and $27 \mathrm{~h}$ mouse motion per week (Percept Technology Labs, 2004). The MS 'Intellimouse' uses three energy management system (EMS) levels to minimize energy consumption. Addition- 
a

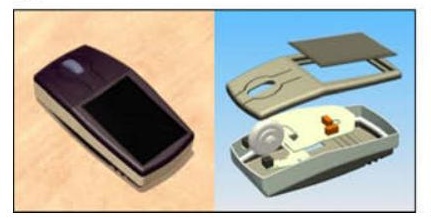

b

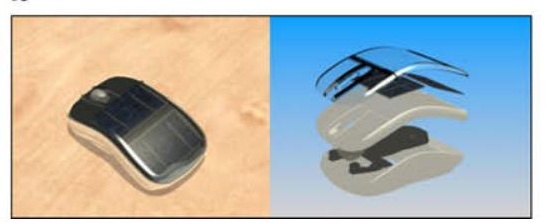

C

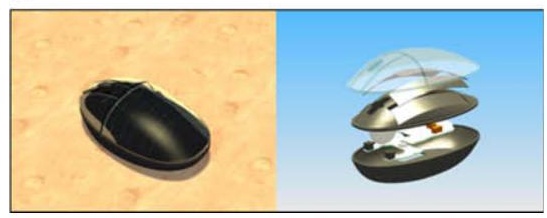

Fig. 1. Integration of different PV cell types using different encasing shapes and cell technologies, with (a) flat panel integration as part of outer encasing; (b) crystalline series connected cell integration; (c) bent a-Si:H on foil solar cell integration.

Table 1

Rated power of different types of computer mice

\begin{tabular}{llll}
\hline Type of mouse & \multicolumn{3}{l}{ EMS-mode (1-active, 2-sleep, 3-deep sleep state) } \\
\cline { 2 - 4 } & $1[\mathrm{~mW}]$ & {$[\mu \mathrm{W}]$} & {$[\mu \mathrm{W}]$} \\
\hline Wireless optical & 7 & 570 & 90 \\
\multirow{2}{*}{ Wired optical } & 37 & 211 & 470 \\
& 400 & - & - \\
Ball-based & 500 & - & - \\
& 75 & - & - \\
& 150 & - & - \\
\hline
\end{tabular}

ally, battery runtime is increased by underlay material dependent LED intensity. A DC/DC converter provides the mouse circuitry with sufficient voltage $(3.5 \mathrm{~V})$ with (primary) battery voltages as low as $0.6 \mathrm{~V}$. Surprisingly, this product is not equipped with a simple energy-saving 'on/ off'-switch, which enables users to indisputably switch off the device, but relies on 'sleeping mode' activation. When mice are transported (e.g., with a laptop) no 'sleeping' mode will be activated. The user cannot prevent the device wasting energy.

The amount of PV generated charge depends on the solar cell area, effective solar cell efficiency and the amount of available irradiation. Active solar cell area was initially estimated to be between 20 and $30 \mathrm{~cm}^{2}$, based on typical mouse product dimensions; the final product incorporates $28 \mathrm{~cm}^{2}$ of PV. As the 'effective' PV efficiency depends on several factors, we assumed overall $10 \%$ constant efficiency to reduce complexity (i.e., neither irradiance intensity nor temperature dependent $\mathrm{PV}$ performance is considered and

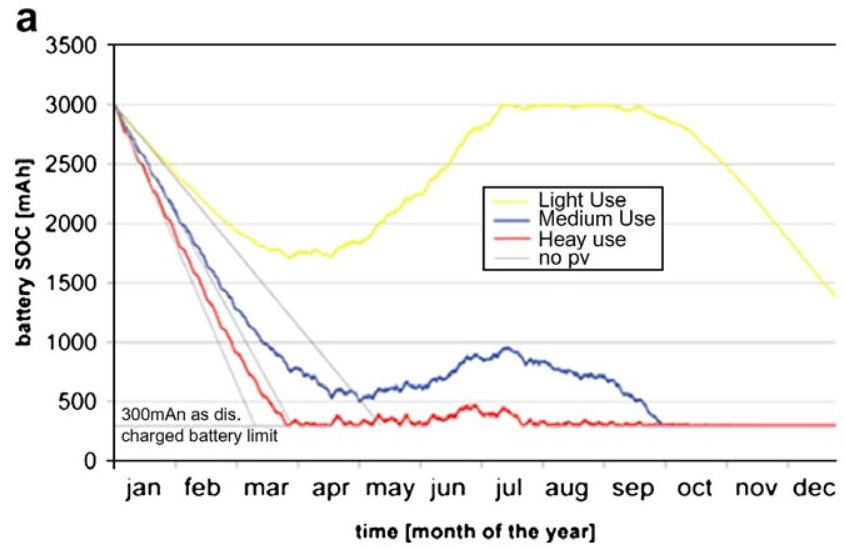

spectral effects are not accounted for). Then the amount of PV generated charge can be easily estimated based on irradiance time series. For this, we used hourly averaged, global horizontal irradiation measured in 2005 in de Bilt, The Netherlands. Lower irradiance levels indoors were accounted for by a simple attenuation factor of 0.05 , which is similar to a constant daylight factor (DF) of 5\%. However, the DF is only defined for fully overcast skies, whereas the $5 \%$ assumed here also includes direct irradiance fractions. When the SPM is "sun-bathed", available irradiance levels will be (much) larger. For this case, we assumed a constant DF of $60 \%$, which implies a window sill located in a south-facing room with direct sun-light access. During device use, PV power output is assumed to be zero, as the user's hand then covers the solar cell. Finally, PV generated charge was assumed to be lowered by battery charge efficiency $(90 \%$ constant), battery selfdischarge $(15 \%$ per month) and the efficiency of electronic circuitries $(90 \%$ constant), which also provides maximum power point tracking (with simplified 100\% accuracy). To deal with the many parameters, we developed a computer tool to simulate the energy flows in PV powered consumer systems (Reich et al., 2006).

Fig. 2 shows calculated battery state of charge (SOC) across a whole year, comparing computer mice with and without incorporated PV. Battery SOC of mice without incorporated PV is depicted in both figures by gray lines. For all calculated battery SOC, three different weekly use times of $4 \mathrm{~h}$ (light use), $18 \mathrm{~h}$ (medium use) or $27 \mathrm{~h}$ (heavy use) were assumed. In addition, a "sun-bathed" SPM

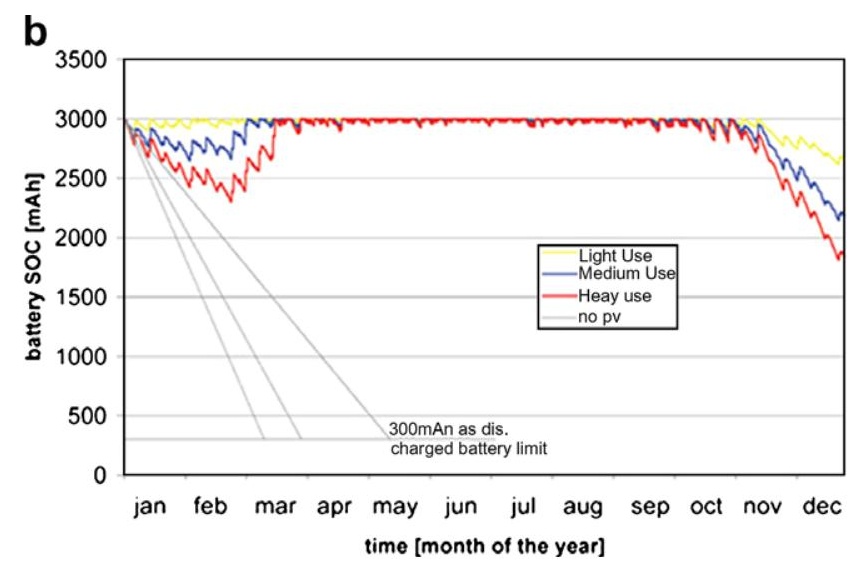

Fig. 2. Battery state of charge (SOC) for a SPM that (a) is and (b) is not "sun-bathed" on a daily basis between 11:30 and 12:30 o'clock (weekdays) and during the whole weekend. Gray lines reflect battery SOC for mice without any PV. 
(Fig. 2a) is compared to a SPM that is not "sun-bathed" (Fig. 2b). Note the influence users have by "sun-bathing" the SPM. The batteries are almost fully charged during the period March-October for assumed "sun-bathing patterns", in which the SPM is exposed to $60 \%$ of global horizontal outdoor irradiation daily during 11:30 and 12:30 as well as during the entire weekend. Comparing both figures (with and without "sun-bathing") also shows the difficulties encountered when dimensioning components, as different optimal battery capacities are associated to each scenario. For the "sun-bathing" scenario chosen here, the optimal battery capacity would be 1900, 1250 and $500 \mathrm{mAh}$ for heavy, medium and light device use, respectively, i.e., the minimum battery capacity required for granting year-round product operation on $100 \% \mathrm{PV}$ generated charge. When mice are not "sun-bathed" at all, however, battery capacity will be only sufficient for light use. It would therefore be very helpful, if typical charge yields related to "sun-bathing" activity could be defined quantitatively. Unfortunately, this is rather difficult. Although the term "sun-bathing" indicates that direct sun-light access is compulsory, one can argue that users who place their SPM on a window sill with access to only diffuse solar radiation also do "sun-bath" their device. Typical charge yields cannot be found, if both direct and only diffuse fractions of solar radiation are considered for given durations of "sunbathing". We therefore decided to focus on only if and how long users are willing to pro-actively place their SPM at a specific indoor location, which either means considerable higher daylight availability (of diffuse irradiance) or direct sun-light exposure, respectively.

\subsection{Design criteria}

Based on the exploratory studies and the energy balance estimations we defined "design criteria". First, the following energetic requirements were agreed upon:

- When fully charged, the SPM must allow five days work without irradiation.

- The SPM must indicate when 'sun-bathing' is required (before the battery runs flat).

- The design should stimulate the user to 'sun-bath' the SPM.

- The incorporated PV and charge storage unit should provide all-year-round product operation, if the mouse is 'sun-bathed' adequately.

- The user manual must clearly state how much 'sun-bathing' is required.

Furthermore, the SPM must be equipped with a scroll wheel and two push buttons, must guarantee a product lifetime of at least five years and be RoHS compliant. ${ }^{1}$ The

\footnotetext{
${ }^{1}$ The European directive 2002/95/EG forces the "Restriction of the use of certain hazardous substances" in electrical and electronic equipment (RoHS).
}

concept should also enable the manufacture of prototypes at a later stage. The potential concepts should be evaluated as if the SPM was to be produced in a commercial setting. To allow for (theoretical) mass production, the individual components must be commercially available. Finally, users should perceive the SPM as a quality product, not as a gadget. Here, focus group investigations (see Section 2.1) indicated users could perceive the SPM as a (high) quality product based solely on design aesthetics. Therefore, only a single PV-cell that follows the encasing's shape should be used, to avoid bad user perception on the SPM prototype design. Fig. 3 shows the various components of a SPM in accordance to the defined device criteria. The solar cell is, as depicted, flat and rigid.

\section{System options and component selection}

To eventually build prototypes, a certain system setup must be chosen and each system component must be dimensioned. The following addresses the selection of an adequate battery and PV type, solar cell incorporation and charge controller options.

\subsection{Battery unit}

First, we evaluated typical battery parameters based on available battery handbooks (Buchmann, 1997; Crompton, 2000; Electus Distribution Catalogue, 2001; Linden and Reddy, 2002). ${ }^{2}$ This narrowed the possible choices down to the following battery types: nickel-cadmium ( $\mathrm{NiCd})$, nickel metal hydride (NiMH), lithium ion (Li-ion), sealed lead acid (SLA) and rechargeable alkaline manganese (RAM).

Due to the difficulty in dealing with the many battery parameters, we assessed each technology in five respects: cost, efficiency, design, durability and environmental aspects. We applied a sort of 'fuzzy-logic' approach, as we categorized the specific battery technologies' performance as very bad (--), bad $(-)$, good $(+)$ and very good $(++)$ in the SPM product case (Fig. 4). Categorization took the above mentioned battery handbooks as well as the expertise of the involved $\mathrm{PV}$ and industrial product designers into account. From this, only two battery types were considered further: the NiMH and the Li-ion, as these did not have a very bad score in any category (NiMH) or only fell short on cost and durability grounds (Li-ion).

The decision for either battery type was difficult, but we eventually opted for NiMH batteries for various reasons. For one, NiMH batteries are available in different shapes

\footnotetext{
${ }^{2}$ Parameters considered were energy density [Wh kg-1] and [Wh $\mathrm{cm}-3$ ], cycle life, charging time, overcharge tolerance, self-discharge, open circuit cell voltage (cell potential), maximum discharge rate (max. load current), operation temperature, maintenance requirement, price, efficiency, cycle depth characteristics, commercially available capacities at standard battery sizes (i.e., AA, AAA sized batteries), discharge profile and lifetime as well as toxicity.
} 


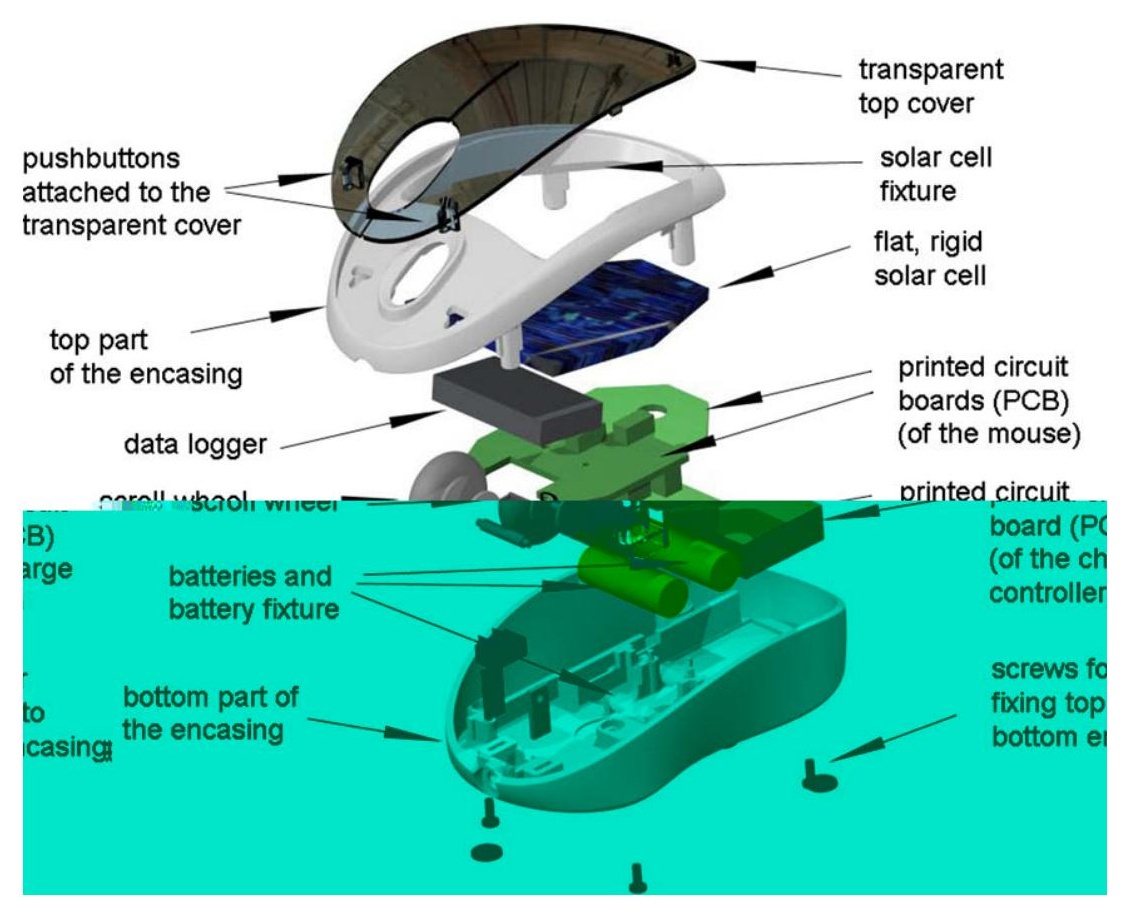

Fig. 3. Components of a SPM.
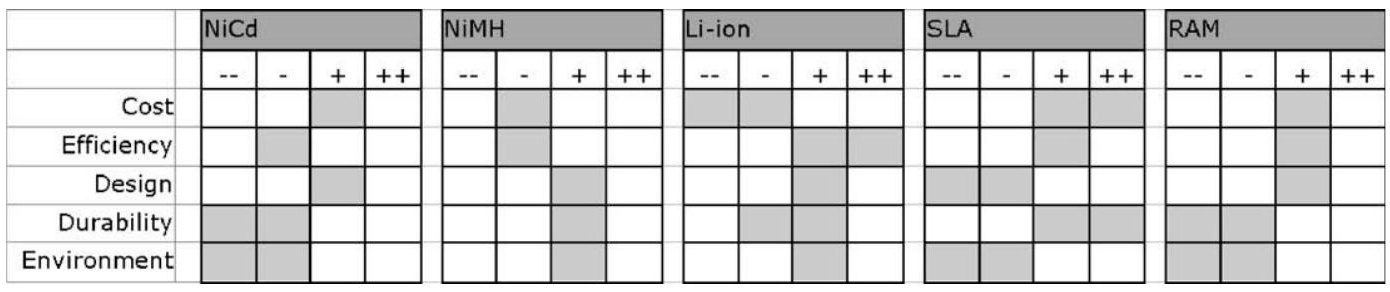

Fig. 4. Assessment of different battery types for the use in SPM.

and capacities, and voltages are multiples of $1.2 \mathrm{~V}$, which allows a lot of freedom regarding system design. Furthermore, NiMH battery types can be found in electronic retailers or supermarkets, making it easy for the user to exchange these secondary batteries, if required. Their high self-discharge no longer poses a problem, as nowadays NiMH batteries with almost no self-discharge are available (SANYO, 2006).

\subsection{PV type selection}

Thin film PV technology, especially hydrogenated amorphous silicon (a-Si:H) based solar cells, are often argued to suit PV powered products better than crystalline silicon cells. Indeed, the a-Si:H cell type shows outstanding weak light performance, and the spectral response (SR) matches indoor irradiance spectra very well, as we discussed in Reich et al. (2005). Especially advantageous is that the $\mathrm{SR}$ of a-Si:H cells almost matches the photopic response curve of the human eye, which makes a-Si:H cells highly effective at energy efficient artificial lighting conditions. However, under for example fluorescence tube spectra of e.g. 100-150 Lux illumination intensity the charge demands of the SPM simply cannot be met SPM charge demands cannot be met. Thus, the SPM requires solar energy as irradiance source, as the energy flux of solar radiation is orders of magnitude higher than for (energy efficient) artificial lighting conditions. Especially if the SPM is placed at or close to the window sill (see "sun-bathing" in Section 2.2), rather high irradiance intensities will be available for charge generation. Solar cell efficiencies at higher irradiance levels (i.e., $100-1000 \mathrm{~W} / \mathrm{m}^{2}$ ) are generally much better for mono- or multi-crystalline silicon (c-Si and $\mathrm{mc}-\mathrm{Si}$ ) than for a-Si:H solar cells. Commercially available c-Si cells have above 20\% efficiency at STC (Sunpower Corp, 2008), outperforming a-Si:H cells with roughly $7 \%$ STC efficiency by a factor three. ${ }^{3}$

We thus opted for crystalline silicon based cells. Design software (SOLIDWORKS, 2008) indicated, that incorporating such flat, rigid solar cells is feasible (Fig. 5).

\footnotetext{
${ }^{3}$ Standard Testing conditions (STC) are defined as $1000 \mathrm{~W} / \mathrm{m}^{2}$ irradiance at Air Mass (AM) 1.5 spectrum and $25^{\circ} \mathrm{C}$ temperature.
} 


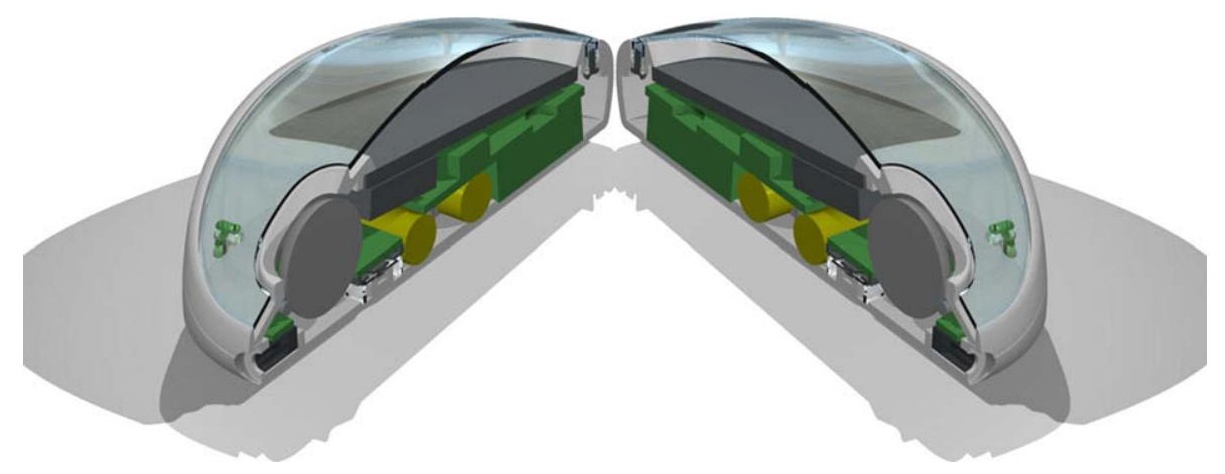

Fig. 5. Example of incorporating a flat, rigid PV cell/module into a SPM.

\subsection{PV incorporation: the optics of the encasing}

Placing the solar cell underneath a double-bent, transparent plastic cover within the SPM encasing reduces irradiance intensity, which in addition is unequally distributed across the solar cell due to shading effects. Interestingly, the product encasings' shading effect is slightly overcompensated by optical concentration, as calculated by the software tool 3D-PV and shown in Fig. 6 (Reinders, 2007). Since the 3D-PV tool could not calculate double-bent interface characteristics, however, this does not include transparent cover transmission characteristics, which we estimated together with transmission characteristics of a two-paned window glazing system using Fresnel equations in a separate model. Here, we found PV module tilts, i.e., the tilt of the solar cell within the SPM encasing, of 20 $30^{\circ}$ to be optimal. In the final concept the solar cell is tilted by only $10^{\circ}$, due to a trade-off between the SPM's ergonomics and the required space for electronics, batteries and mechanics. This permits relatively large cells to be incorporated without sacrificing too much internal space. To improve 'light harvesting properties', support structures should be designed for fixed and secured positioning of

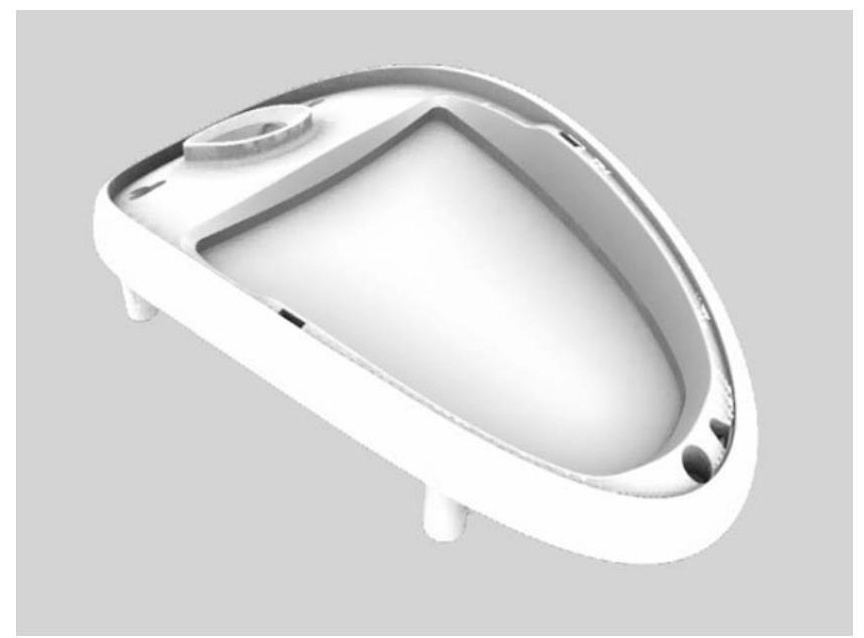

Fig. 6. Modeling effects of the product encasing on irradiance reaching the cell.
SPM's with about $45^{\circ}$ tilt angle when placed for a "sunbath" at a window sill.

\subsection{Charge controller options}

The most simple charge controller would only require a single diode, preventing battery discharge (i.e., with the solar cell as a consumer). Overcharge protection could already be achieved by just another diode, which short-circuits the solar cell above a certain voltage threshold. Another option would be a "self-regulating" system design, by matching maximum solar cell voltage to maximum storage unit voltage. This would be desirable, owing to the sheer simplicity. However, matching battery and PV voltage is difficult, because battery voltage is battery state of charge (SOC) dependent, and PV voltage is irradiance intensity dependent. Voltage converters, on the other hand, require rather complex electronics, but also lead to greater design freedom. Theoretically, when incorporating a voltage stepping unit, all combinations depicted (Fig. 7) for the three categories 'storage', 'module set-up' and 'PV technology' become possible. As voltage converters apply DC/ DC up- or down-conversion (of PV voltage), they are most logically considered in combination with maximum power point tracking. With the single cell concept already chosen, we opted for charge controller electronics that perform voltage up-conversion and maximum power point tracking.

On top of charge controlling, the electronics should provide a battery status indication, as defined in the "device criteria" (Section 2.3). It was decided to only use battery voltage as battery SOC indication. Here, the selected NiMH battery type only allows indicating battery SOC as either 'full' or 'almost empty', due to rather SOC independent voltage potential of NiMH batteries. It would be desirable to indicate battery SOC through a bar graph composed of four or more elements. Moreover, indicating the positive influence of "sun-bathing" may encourage users to "sun-bath" the mouse more regularly. However, we opted for a relatively simple but cheap and fast solution. Note that chip companies recently started to offer integrated circuits (ICs) dedicated to solar cell applications (e.g., TPS61200 from Texas Instruments). If this trend con- 


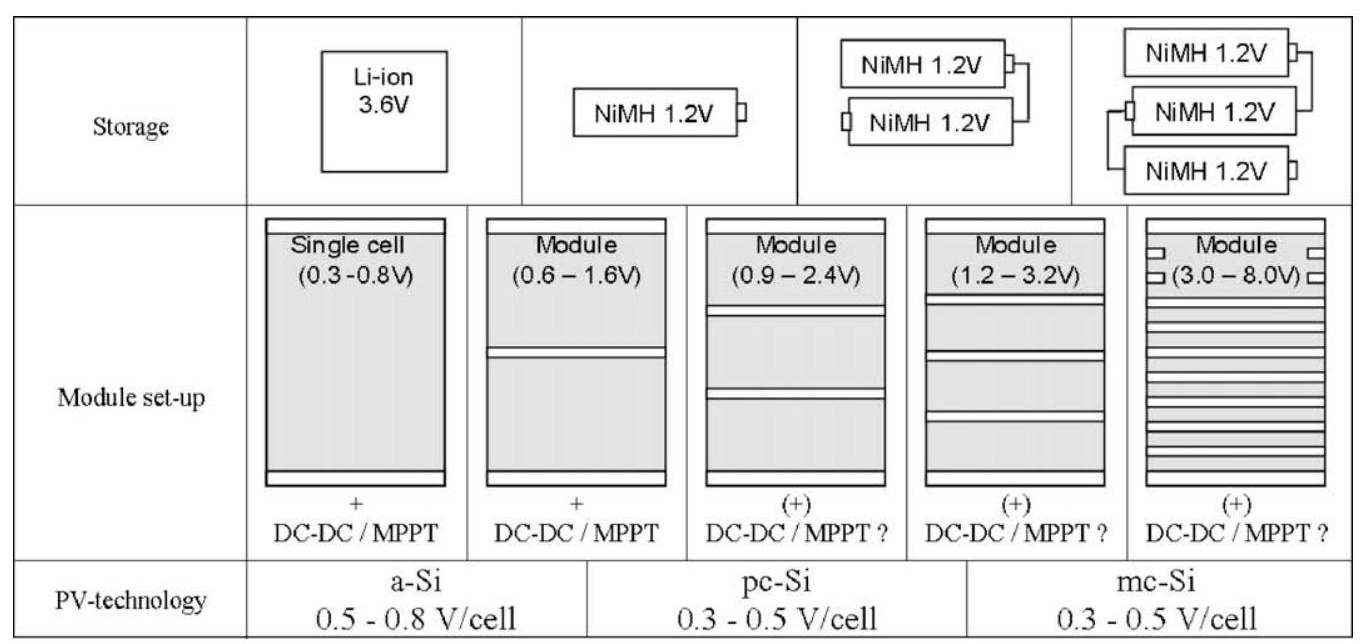

Fig. 7. Morphological chart of possible SPM designs concerning solar cell implementation and the possible voltage ranges of the different subcomponents.

tinues, future ICs can be expected to allow for easier electronic integration including improved SOC indication for PV powered electronic systems.

\section{The final SPM concept, user tests and concept evaluation}

Fifteen SPMs were manufactured using commercial mice electronics and rapid prototyping-based plastic encasings. Although the incorporated PV cell is flat and rigid, curved lines and double-bent surfaces dominate the design. Fig. 8 shows the final SPM design together with the support structure to give an impression of the design aesthetics.

\subsection{SPM prototype specifications}

The 15 SPM prototypes were manufactured in accordance to the different options discussed in Section 3. A voltage converter (DC/DC voltage up-conversion) charges the battery (of NiMH type of AAA size and $800 \mathrm{mAh}$ capacity), if is the PV voltage is above $0.3 \mathrm{~V}$. The voltage converter applies maximum power point tracking by measuring the IV curve of the incorporated c-Si or mc-Si solar cell every $10 \mathrm{~s}$ and adopting pulse-width-modulation based switching frequency. The voltage converter is incorporated on the PCB of the additionally incorporated charge controller, which protects the batteries from both deep discharge and overcharge. Should defined voltage thresholds be exceeded, either the solar cell or the mouse PCB is disconnected from the battery. Battery SOC indication already calls for improvement without user tests: a red LED blinks, when battery voltage is below a certain voltage threshold. Nothing, however, indicates an (almost) fully charged battery. Note that we incorporated a smaller battery capacity than we consider optimal for a commercial product, to ease prototype assembly. In addition to SPM design features discussed in Section 3, it is possible to recharge the battery by connecting the SPM to a USB port. This allows test users to continue working with the SPM should PV generated charge be insufficient.
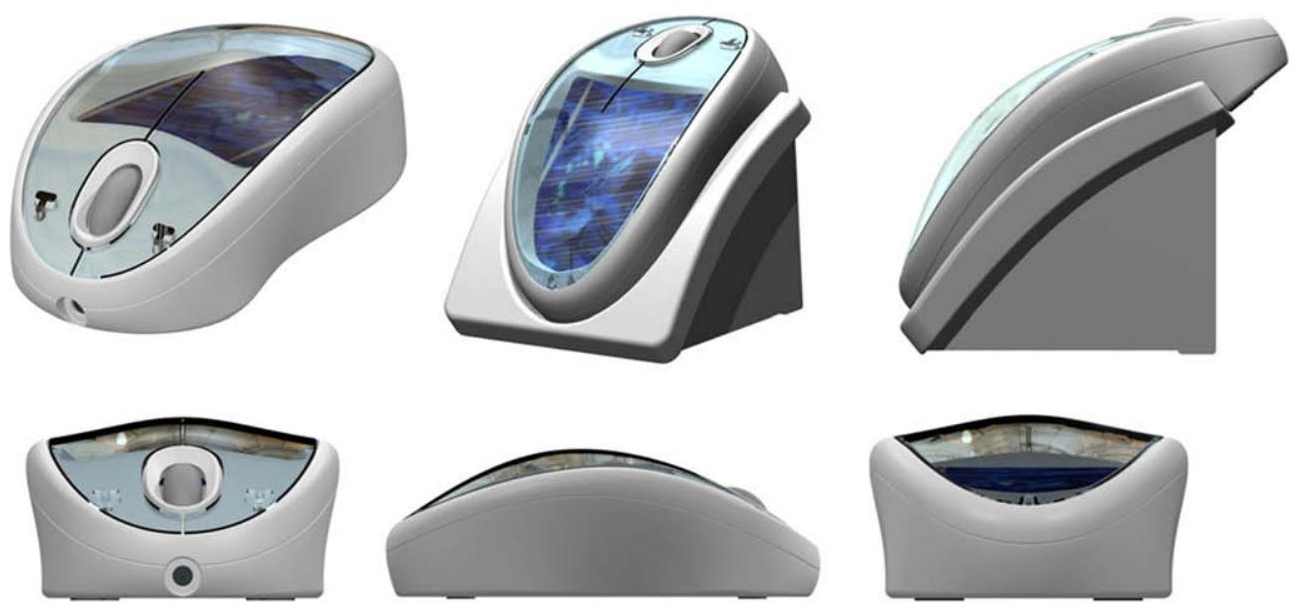

Fig. 8. Rendered pictures of the final SPM design concept. 
Eighteen users tested the SPM at their office desktops in Delft, Twente, and Utrecht, The Netherlands, during October and December 2007. Six participants tested the SPM for over seven weeks, the other twelve for only a month. User interviews allowed in-depth understanding of the individual user concerns; however, the limited number of test users allowed only qualitative conclusions to be drawn.

The general satisfaction of users with the SPM prototypes greatly diverged. At the start of the test period, most users indicated the mouse to be 'very big' or even 'bulky'. Nevertheless, as the test phase continued, users adjusted to product dimensions so that, once the test period drew to an end, some users actually indicated to prefer a larger mouse with dimensions equal to the SPM. The influence of different product geometries, however, was apparently underestimated during the design process, as this issue (negatively) concerned almost half of the users at the beginning.

The quality of battery SOC indication was perceived as insufficient by all users, irrespective of "sun-bathing" willingness. Suggestions on possible improvements greatly diverged. The majority would be satisfied with a simple battery status indicator as used in, e.g., mobile phones. Some desired more sophisticated solutions, especially those "sun-bathing" the SPM on a daily basis. Independently, three of these test users suggested that the SPM energy balance should be accessible via the computer using specific SPM software to adopt optimal "sun-bathing" strategies.

Although "sun-bathing" was accepted by users remarkably well, it was interpreted in a way that did not include direct sun-light exposure (see Section 2.2). Users working at indoor locations with no access to direct sun-light did not move their mice into direct sun-shine, i.e., to a window sill at another room when the current weather conditions was sunny. However, users agreed that placing the mouse on the window sill at their specific work-place could be easily synchronized with their daily or weekly work routine. Consequently, roughly two-thirds of all users placed their SPM on the window sill almost every weekend, roughly one-third on a daily basis, and only one user refused to do so in principle. Future research should investigate more quantitatively in how far, how many users are willing to "sun-bath" their PV device. Particularly interesting is in how far charge harvesting potentials related to "sun-bathing" are affected when direct sunshine is defined obligatory or not. This is important, as direct sunshine implies very high energy densities so that much shorter "sun-bathing" durations would be required. Some of the SPM prototypes were tested at indoor locations, however, where solely diffuse solar radiation reached the window sill. Hence, "sunbathing" requirements differ widely from those assumed in the preliminary assessments in this study (see Section 2), which suggested sunshine exposure for "sun-bathing" activity. Furthermore, window glazing with "low-e" coat- 
harvesting properties" to eventually reduce "sun-bathing" requirements during daily $\mathrm{PV}$ powered product use.

\section{Acknowledgement}

We would like to thank Bas Wardenaar and Gert-Jan Langendijk from ECN for laser scribing c-/mc-Si cells, Matthias Schillen and Katrin Malinowski from (RWE) Schott Solar for providing a-Si:H cells, Angele Reinders and Hugo de Wit from the University of Twente for rendering illumination distributions using the 3D-PV tool, Bamshad Houshiani for help during prototype assembly, and finally all members of the SynEnergy group, particularly Boelie Elzen for his efforts regarding user related aspects and preparing qualitative user interviews, Matthijs Netten, without whom prototype-assembly and the qualitative user interviews had not been possible, and Sioe Yao Kan and Jaap Jelsma for contributions during the early stages of the project. This work is part of the SYNEnergy project, which is financially supported by the NWO/SenterNovem Energy Research programme.

\section{References}

Acopian Inc., 2008. <http://www.acopian.com/radiohome.html $>$ (accessed 20.02.08).

Alsema, E.A., Elzen, B., Reich, N.H., van Sark, W.G.J.H.M., Kan, S.Y., Silvester, S., Veefkind, M., Jelsma, J., 2005. In: Proceedings of the 20th European Photovoltaic Solar Energy Conference, Barcelona, pp. 1981-1984.

Buchmann, 1997. Batteries in a Portable World. EC\&M Books.
Chapin, D.M., Fueller, C.S., Pearson, G.L., 1954. A new silicon p-n junction photocell for converting solar radiation into electrical power. Journal of Applied Physics 25, 676.

Crompton, 2000. Battery Reference Book. Butterworth-Heinemann.

Electus Distribution Catalogue, 2001. Soanar Plus Ltd.

Elzen, B., 2006. Personal Note and Internal Project Report, unpublished result, Utrecht.

Kan, S.Y., Van Beers, S., Brezet, J., 2004. Maturely designed and sustainable PV powered products. In: Eurosun 2004 Proceedings, Freiburg.

Linden, D., Reddy, T.B., 2002. Handbook of Batteries. McGraw-Hill Handbooks.

Percept Technology Labs, Boulder Colorado, 2004. The online version may be accessed at: $<$ http://download.microsoft.com/download/1/3/ 9/139a8c30-34cc-4453-a449-7a1c586a3ae5/MicrosoftMouseBatteryExecSummary.pdf $>$ (accessed 20.02.08).

Reich, N.H., van Sark, W.G.J.H.M., Alsema, E.A., Kan, S.Y., Silvester, S., van der Heide, A.S.H., Lof, R.W., Schropp, R.E.I., 2005. In: Proceedings of the 20th European Photovoltaic Solar Energy Conference, Barcelona, pp. 2120-2123.

Reich, N.H., van Sark, W.G.J.H.M., Alsema, E.A., 2006. In: Proceedings of the 21st European Photovoltaic Solar Energy Conference, Dresden, pp. 2301-2305.

Reinders, A.H.M.E., 2007. In: Proceedings of the 22nd European Photovoltaic Solar Energy Conference, Milan, pp. 2737-2739.

Roth, W., 2008. 40 Jahre Photovoltaik-Geräte-Entwicklung in Deutschland, Tagungsband 23. In: Symposium Photovoltaische Solarenergie, Bad Staffelstein, p. 110.

SANYO, 2006. Eneloop Product Datasheet, NiMH Batteries, <www. sanyo.com $>$ and <http://www.eneloop.info/>, respectively (both accessed 20.02.08).

SOLIDWORKS, 2008. <www.solidworks.com> (accessed 20.02.08).

SunPower, Datasheet A300 Solar Cell, <www.sunpowercorp.com> (accessed on 26.05.08) 